\title{
Relaçóes de Poder no Império Assirio: Arqueologia e Iconografia da Conquista de Lakiš
}

\author{
Katia Maria Paim Pozzer \\ Universidade Luterana do Brasil
}

\begin{abstract}
The Assyrian came down like the wolf on the fold, And his cohorts were gleaming in purple and gold; And the sheen of their spears was like stars on the sea,

When the blue wave rolls nightly on deep Galile ${ }^{1}$. The Destruction of Sennacherib, Lord Byron (1788-1824).
\end{abstract}

\section{Introduçáo}

O presente artigo é parte das conclusóes preliminares do projeto de pesquisa "Guerra e Religião - Estudo de textos e imagens do mundo antigo oriental". Este projeto tem por objetivo compreender a relação entre a religiăo e os conflitos militares que marcaram a constituição do grande império neoassírio na Antiguidade ${ }^{2}$ e conta com apoio do Conselho Nacional de Desenvolvimento Científico e Tecnológico (CNPq-Brasil) e da Fundação de Amparo à Pesquisa do Estado do Rio Grande do Sul (FAPERGS).

As civilizaçôes antigo-orientais, dentre elas a egípcia, a israelita, a assíria, a babilônica e a hitita destacaram-se pela concepçáo religiosa do mundo, da criação do Homem e das coisas. $\mathrm{Na}$ Mesopotâmia, em particular, acreditava-se que o mundo divino interferia na realidade cotidiana dos homens e que os deuses, tanto podiam amenizar os sofrimentos humanos, como castigá-los por suas más açôes. Para poder explicar estas relaçóes, escribas e sacerdotes criaram narrativas literárias que tratavam das mais variadas questóes.

\footnotetext{
${ }^{1}$ Como lobo no aprisco, os assírios atacaram, com legióes reluzentes, de púrpura e ouro, o brilho de suas lanças, qual estrelas na água azul, quando ondas noturnas agitavam o mar da Galiléia. ${ }^{2}$ As atividades de pesquisa são desenvolvidas no Laboratório de Pesquisa do Mundo Antigo (LAPEMA), do Curso de História da Universidade Luterana do Brasil (ULBRA). 
Esta documentação inclui desde mitos cosmogônicos, até textos que relatam a fundação de cidades, passando por composições mágico-medicinais ${ }^{3}$. Além desta vasta documentação epigráfica, encontramos uma parcela significativa de fontes imagéticas onde está representada a riqueza simbólica da relação do homem com o divino. A religiáo, portanto, adquiriu, nos relevos parietais assírios do I milênio a. C., uma forte amplitude para a compreensão da história e do imaginário daquela civilização.

O I milênio a. C. no Oriente Próximo pode ser qualificado como a idade dos impérios: do século IX ao século I a. C. foram criados cinco grandes impérios: o neoassírio, o neobabilônico, o persa, o helenístico e o parta. $\mathrm{O}$ centro de gravidade política destas civilizaçôes estava inicialmente centrado na Mesopotâmia, depois oscilou, ora em direção ao Irã, ora em direção ao Mar Mediterrâneo.

O espaço geográfico que serviu de cenário para estes eventos era composto de diferentes regiôes. Segundo seus habitantes, o mundo estava dividido em quatro regióes, ordenadas segundo os pontos cardeais: no norte, o país de Subartu, a Assíria, zona montanhosa; a oeste, o país de Amurru, próximo ao Mediterrâneo; a leste, o país do Elam, no planalto iraniano e ao sul, o deserto do Nefud e de Nedjed.

No norte, o espaço que separava os dois grandes rios, o Tigre e o Eufrates, formava a planície do Djezireh ou Alta Mesopotâmia. A leste desta zona, entre as margens do Tigre e as colinas dos Montes Zagros, separando a Mesopotâmia do planalto iraniano, estava a Assíria. $\mathrm{Na}$ região da Alta Mesopotâmia, praticamente desprovida de cidades, algumas implantaçôes urbanas se constituíram ao longo do Tigre e, no II milênio a. C., foram reunidas para formar o estado assírio e ficaram conhecidas como o Triângulo Assírio: Nínive, Arbela e Aššur ${ }^{4}$.

\footnotetext{
${ }^{3}$ K.M.P., POZZER. "A Magia na Mesopotâmia". In: P.P., FUNARI; J.G., SILVA; A.L., MARTINS (Orgs.). História Antiga - contribuiçóes brasileiras. São Paulo: FAPESP/Annablume, 2008, p.186.

${ }^{4}$ F., JOANNÈS. La Mésopotamie au 1er millénaire avant J.-C. Paris: Armand Colin, 2000,p. 10.
} 


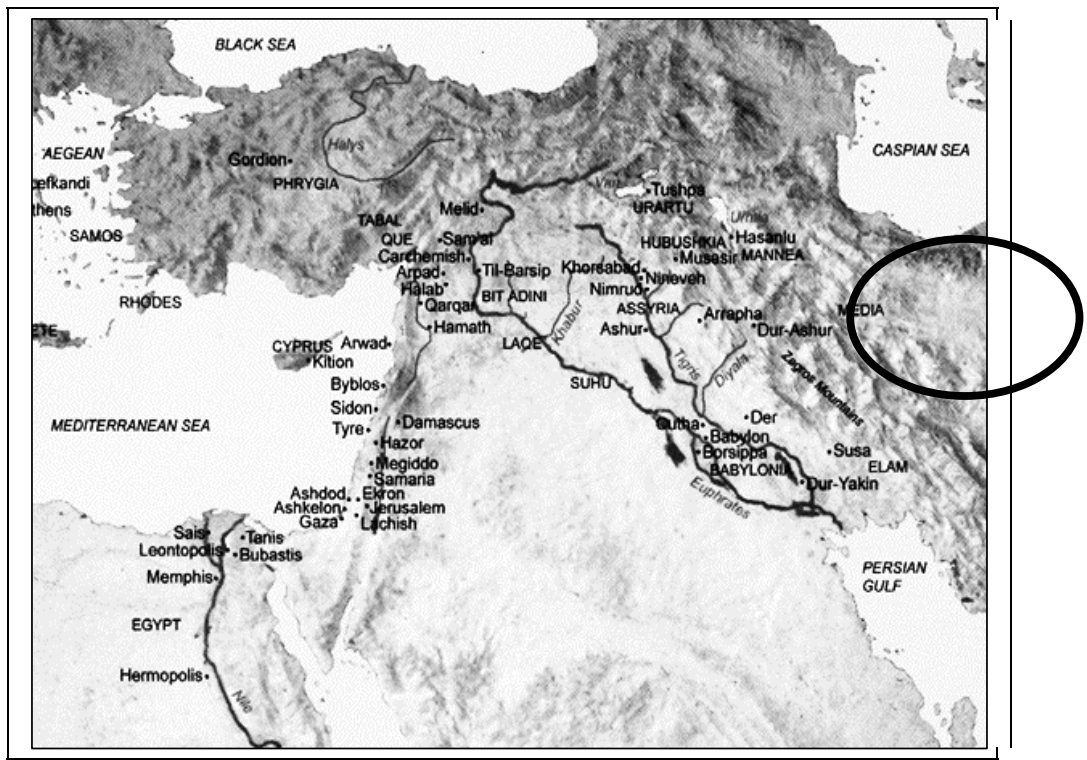

Fig. 1 - Mapa adaptado da obra de Collins ${ }^{5}$.

As fronteiras entre os sistemas políticos modernos são geralmente ilustradas por mapas com linhas sólidas, mas sabemos que estas "linhas" não são barreiras para o livre fluxo de pessoas e mercadorias entre os Estados. A ideia de fronteira é um conceito moderno, associado a limites políticos e administrativos de Estados modernos. Parker ${ }^{6}$, em seu estudo sobre os mecanismos do império assírio, assegura que os limites políticos não são adequados para identificar os limites linguísticos e, por isso, ele opta por fazer uma distinçâo entre os conceitos de "border" e "frontier". Para o autor, "border" seria uma fronteira linear, já "frontier" seria uma área ou zona de transiçấo entre duas regiōes ou identidades políticas diferentes e argumenta que esta última definição está muito próxima do que as evidências arqueológicas e textuais nos mostram. $\mathrm{Na}$ pesquisa realizada na regiâo do império assírio fronteiriça com a Anatólia ele identificou uma zona de transição dinâmica, de

\footnotetext{
${ }^{5}$ F., JOANNÈS. (Org.). Dictionnaire de la Civilisation Mésopotamienne. Paris: Robert Laffont, 2001, p.129.

${ }^{6}$ B.J., PARKER. The Mechanics of Empire. The Northern Frontier of Assyria as a case Study in Imperial Dynamics. Helsinki: University of Helsinki, 2001, p.11.
} 
interação entre o poder consolidado do império assírio e diferentes graus de variaçôes de centralização política do sudeste da Anatólia. Assim, entendemos que se faz necessária certa relativização dos conceitos de fronteira para entendermos o mundo antigo-oriental.

\section{A constituição do Império Assírio: estudo do tempo e do espaço}

Podemos reconhecer duas grandes fases na formação do império assírio: do século XIII a. C. até o ano 1.000 a. C., aproximadamente, e do ano 1.000 a. C. até a queda de Nínive em 612 a. C. A primeira fase iniciou-se com a emancipação local e regional até as primeiras expediçôes militares fora do território mesopotâmico, onde se destacam os reis Tukulti-Ninurta I (12431207 a. C.) que venceu Babilônia e Tiglat-piliser I (1112-1074 a. C.). A segunda fase assistiu a extensão da hegemonia política, cada vez mais profunda e longínqua, do império assírio, chegando ao Mediterrâneo. Inúmeros soberanos colecionaram vitórias em campanhas militares, de Assurnazirpal II (883-859 a. C.) à Assurbanipal (668-631 a. C.), e narraram estes eventos em baixos-relevos em seus palácios.

O surgimento do reino de Assíria deu-se por volta ou 1400 a. C., quando uma sucessão de reis transformou uma antiga cidade mercantil, que atuava como centro de culto religioso do deus Aššur, em núcleo de poder político. Mas a consolidação do estado assírio ocorreu com os reis Assurnazirpal II e seu filho Salmanassar III que, de 934 a 827 a. C., empreenderam a conquista dos territórios que haviam sido ocupados pelos arameus no II milênio a. C. e formaram um vasto império que se estendeu até o Mar Mediterrâneo. Após este rápido processo de expansão, transcorreu cerca de oitenta anos de conflitos internos, com crises sociais, em que a Assíria era ameaçada pelo importante reino de Urartu, na Anatólia. Mas, quando o rei Tiglath-phalasar III assume o trono (744-727 a. C.), ele inicia uma política de conquistas em todo o Oriente Próximo ocidental. Este momento marca uma mudança de paradigma, pois o antigo reino tradicional vai dar lugar a um império, com o poder centralizado em torno da figura do rei, entendido como o único detentor de autoridade e legitimado pelo clero. 
Após uma primeira restauração do Estado por Aššur-dan II (934-912 a. C.), em um país que ainda sofria com a fome, uma grande conquista é empreendida por Adad-Nêrâri II (912-891 a. C.) que é seguida por TukultiNinurta II (890-894 a. C.). Ao longo de um quarto de século Assurnazirpal II (883-859 a. C.) desenvolveu, de maneira espetacular, o poderio assírio e praticou uma política de terror e de terras arrasadas contra aqueles que resistiam ao subjugo, com pesadas cobranças de tributos. Com esses atos ele se apropriou dos recursos naturais e humanos, reutilizados para o esforço de guerra e alcançou ao Mar Mediterrâneo a partir de 876 a.C.

Šamši-Adad I interveio em Babilônia e a conquistou em 813 a. C. Ele foi sucedido por Adad-nêrârî III (810-783 a. C.) que perde o poder e sofre forte influência política de sua mãe Sammuramat. Um longo período de crises e sucessóes transcorre até que, em 744 a. C., Tiglat-piliser II toma o poder e restabeleceu, pela força, o império assírio. Em 743 a. C., ele vence uma coalizão de Urartu com os estados arameus da Síria e deporta 72.950 prisioneiros, anexando o reino de Arpad. Em 738 a. C. submete a costa Mediterrânea, Israel e Judá e deporta 303.000 pessoas e, dez anos mais tarde, conquista a Babilônia ${ }^{7}$.

Uma nova dinastia se instalou no poder e consolidou o império assírio com os reis Sargão II, Senaqueribe, Esarhaddon e Assurbanipal. Sargáo II (721705 a. C.) realizou um feito excepcional, a criação de uma nova capital, com a construção da cidade de Dûr-Šarrukin. Ele ainda transformou o reino de Israel em uma província assíria e abriu vários campos de batalha em regióes distantes umas das outras, dificultando o controle das operaçóes militares. Morreu em uma emboscada na regiáo de Tabal, noroeste do império, em 705 a. C. Seu filho Senaqueribe (704-681 a.C.) herdou o trono e enfrentou uma grande crise com a Babilônia. Em 701 a. C., ele tenta conquistar o Estado de Judá, mas durante o cerco à Jerusalém, seu exército é vitimado por uma epidemia. Senaqueribe desenvolve novas tecnologias de guerra e quatro anos mais tarde, cerca e destrói a cidade de Lakiš. Este episódio foi narrado em um dos mais belos conjuntos de relevos assírios, hoje pertencentes ao acervo do Museu Britânico, em Londres. Senaqueribe morre assassinado em Kalhu, no templo

${ }^{7}$ F., JOANNÈS. La Mésopotamie au 1er millénaire avant J.-C. Paris: Armand Colin, 2000, p.28. 
do deus Ninurta em 681 a. C. Após sua morte, o país caiu em uma guerra civil e em 680 a. C. Esarhaddon, seu filho, toma o poder e ataca o Egito. Muito doente ele é sucedido por seu filho Assurbanipal (672-627 a. C.), que empreende inúmeras campanhas militares e vence o Elam em 653 a. C. Não temos muitas informaçôes sobre o período final de seu reinado, mas sabemos que Assurbanipal foi derrotado pela coalizão dos exércitos meda e babilônico em 612 a.C., levando à queda definitiva do império assírio ${ }^{8}$.

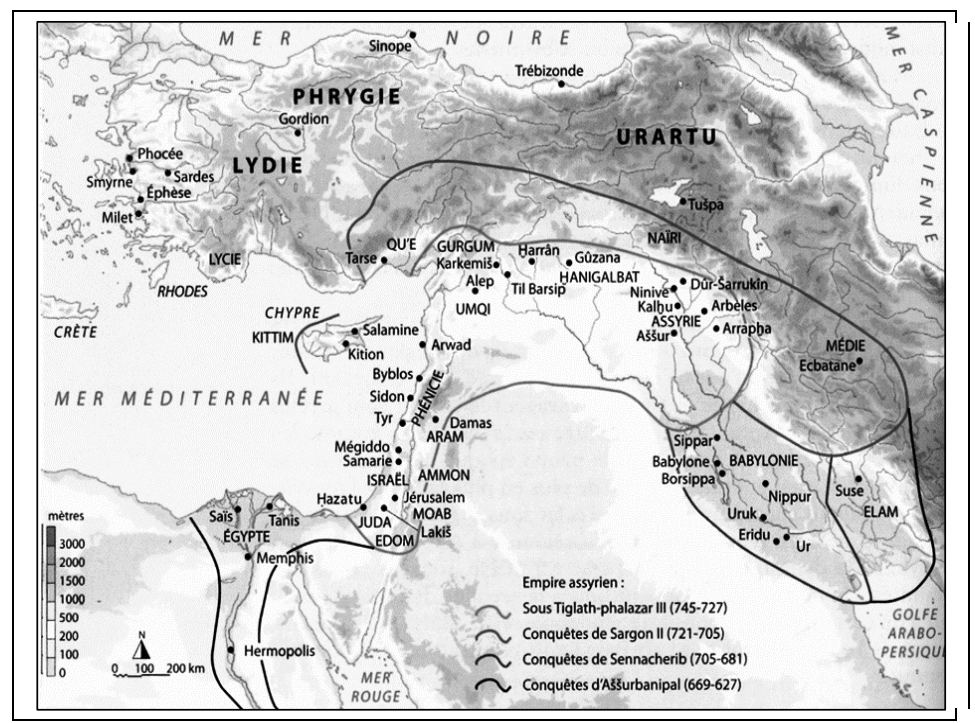

Fig. 2 - Constituição do Império Assírio9.

\section{Império e poder: uma discussão conceitual}

Nos últimos anos, a discussão sobre a ascensão e queda de impérios e estados antigos tornou-se um tema de história política e social comparada e as questốes relativas à dinâmica dos impérios têm sido entendidas como fazendo

\footnotetext{
${ }^{8}$ P., BORDREUIL; F., BRIQUEL-CHATONNET; C., MICHEL. Les Débuts de l'Histoire. Paris: Éditions de La Martinière, 2008, passim.

${ }^{9}$ Ibidem, p. 14 .
} 
parte de amplas transformaçôes culturais, em que as particularidades religiosas, ideológicas e intelectuais desempenham um importante papel.

$\mathrm{O}$ estudo do impacto das mudanças religiosas e intelectuais tem contribuído para elucidar a evolução do sistema político e das estruturas estatais das "civilizaçôes axiais"10 e seu impacto na formação e na trajetória de desenvolvimento das elites políticas e sociais e do sistema ideológico nas diferentes formas do poder. Concordamos com Michael Mann ${ }^{11}$ que vê o Estado como instrumento de coerção e poder ideológico e, ao mesmo tempo, como organismo através do qual as elites podem reproduzir sua dominação.

Já a discussão sobre o conceito de Estado deve considerar as especificidades cronológicas ao longo da história. Podemos sugerir que, no mundo antigo, de um lado podemos ter uma organização político-social na qual um grupo tribal ou comunidade de clã está unido, sob o poder de um guerreiro ou chefe, que possui autoridade simbólica e militar. São os chamados "proto-estados", uma vez que não atingem um grau de permanência institucional, raramente sobrevivem e a autoridade é geralmente exercida sobre um povo nômade em um território livre. De outro lado temos territórios, mais ou menos unificados, com identidade política e organização central, onde um rei ou grupo exerce a autoridade política e mantém o poder por geraçóes. $\mathrm{O}$ elemento-chave desta formação é que o rei/grupo é reconhecido como legítimo e exclusivo e o aspecto religioso é absolutamente fundamental para a formação do Estado. Este tipo mais permanente de Estado pode ser definido como a primeira instância de uma regiáo com territorialidade demarcada, controlada por um governo centralizado, que pode ou náo ter o monopólio do uso da coerção e que geralmente usa seu poder coercitivo para garantir sua autoridade sobre os territórios sob seu poder e, ocasionalmente, com bases punitivas ${ }^{12}$.

\footnotetext{
${ }^{10}$ A expressão "axial age" foi criada por Karl Jaspers, em 1949, para caracterizar o período de formação das maiores religiôes do mundo, entre 600 a.C. e 600 d.C. Estas religióes são distintas de um sistema de crenças, estão baseadas em textos canônicos e foram resultantes de uma transformação cultural das elites, que tornaram-se capazes de teorizar sobre uma visão transcendental do seu mundo e da ordem das coisas. J., GOLDSTONE; J., HALDON. "Ancient States, Empires, and Exploitation: Problems and Perspectives". In: I., MORRIS; W., SCHEIDEL. (eds.). The Dynamics of Ancient Empires. State Power from Assyria to Byzantium. Oxford; New York: Oxford University Press, 2009, p.04.

${ }^{11}$ Ibidem, p.05.

${ }^{12}$ Ibidem, passim. 
Podemos definir poder como a habilidade de um grupo para atingir seus objetivos, obtendo a resposta desejada pela pressão, intimidação ou correção. Poder não está ligado a uma ação direta por parte do dominador, mas sim à percepção que o dominado possui do dominador. Já a força é o uso direto de poderio militar de um grupo para compelir outros para cumprirem suas vontades. A força é dinâmica uma vez que a ação é efetuada. A diferença fundamental entre poder e força é a taxa de energia dispensada. Depois que o poder está estabelecido, ele deve ser mantido por campanhas ideológicas, pelo uso da guerra psicológica ou pela disseminação de propaganda, através de documentos escritos, orais e visuais ${ }^{13}$.

Da mesma forma, o controle central do poder pode representar um elo da corrente entre o Estado local e o império, como os assírios, que controlavam os territórios vizinhos em períodos de expansão territorial, no século IX a. C. De acordo com Parker ${ }^{14}$ :

That empires are expansionist states that hold dominion over diverse subject polities of varying scope and complexity, and that these states are largely concerned with channeling resources from their subject territories to the core polity for the economic benefit and political perpetuation of a limited segment of the population ${ }^{15}$.

O elemento-chave da formação do Estado é a criação de um sistema ideológico e de legitimaçáo complexo, no qual os modos institucionalizados e impessoais de extraçáo da mais valia em sociedades tribais (ou proto-estados) são capazes de se desenvolver. A estrutura burocrática-administrativa confere uma clara vantagem e aparece como uma necessidade do sistema político para manter uma existência não tribal e coesa. Ibn Khaldun ${ }^{16}$, filósofo e analista

\footnotetext{
${ }^{13}$ B.J., PARKER. The Mechanics of Empire. The Northern Frontier of Assyria as a case Study in Imperial Dynamics. Helsinki: University of Helsinki, 2001, p.259.

${ }^{14}$ Ibidem, p.12.

${ }^{15}$ Os impérios são estados expansionistas que mantém a dominação sob vários sistemas políticos de âmbito variável e complexo, e que estes estados estão em grande parte envolvidos com a canalizaçáo de recursos dos territórios sujeitos à política central, para o benefício econômico e a perpetuação política de um segmento limitado da população.

${ }^{16}$ J., GOLDSTONE; J., HALDON. "Ancient States, Empires, and Exploitation: Problems and Perspectives". In: I., MORRIS; W., SCHEIDEL. (eds.). The Dynamics of Ancient Empires. State
} 
político muçulmano, diz que este processo é geralmente seguido de uma formação inicial de entidade política supra tribal com elementos tribais, sob uma liderança, na qual a religiáo tem papel crucial como elemento de unificação, criando uma nova supra realeza com relaçóes identitárias e de lealdade.

O Estado neoassírio do século X ao VIII a. C. parece ter sido capaz de manter um aparato administrativo que, embora apoiado em certo bem-estar social e identidade étnica, era baseado em uma crença religiosa unificada no culto de Aššur. Os elevados tributos, que garantiram uma base estável para a manutenção deste aparato estatal, estavam integrados no sistema de vassalagem e dependência da dinastia real e do culto de Aššur, que era deliberadamente introduzido no panteáo dos povos conquistados. $\mathrm{O}$ sistema hegemônico estava ligado à questão da força e do prestígio do império, isto é, ao seu poder. E, nesta época, o uso da força era a forma mais efetiva para estabelecer e manter o poder.

\section{Relaçóes de poder no interior do Império Assírio}

A designação do império neoassírio advém da denominação linguística do mesmo período, isto é, entre 934 e 605 a. C. A língua falada era o assírio, um dialeto do acádico, usado no sul mesopotâmico ${ }^{17}$. Apesar de ter durado cerca de 300 anos, é possível identificar mudanças no seu caráter, do ponto de vista geográfico, organizacional e de seus modos de dominação política e exploração econômica.

O período considerado de apogeu imperial foi de 721 a 630 a. C., sob os reinados de Sargão II, Senaqueribe, Esarhadon e Assurbanipal, com expansão para o leste, para a Síria-Palestina, chegando ao Mar Mediterrâneo. Neste período, conhecido como "pax assyria", a Assíria dominou as potências

Power from Assyria to Byzantium. Oxford; New York: Oxford University Press, 2009, p.07.

${ }^{17}$ K.M.P., POZZER. "A Palavra de Argila e a Memória da História". In: L., KARNAL; J.A., FREITAS NETO (Orgs.). A Escrita da Memória - Interpretações e Análises Documentais. São Paulo: Instituto Cultural Banco Santos, 2004, passim. 
rivais e estabilizou a organização interna do império. Parte das riquezas arrecadadas foi utilizada nas construçôes monumentais de palácios e templos ${ }^{18}$.

A superioridade do poder militar que garantia a hegemonia assíria estava baseada na ideia da vontade de Aššur de realizar estas conquistas. A expansão assíria foi construída em termos morais e teológicos: era certo e apropriado que os povos vizinhos se submetessem à autoridade assíria, pois isto era sancionado pelos deuses. E a resistência à soberania assíria era entendida como resistência à vontade divina e castigada duramente. Mas os reis assírios também declaravam que a fase de reconstrução, após a conquista, era obra de Aššur e que seria por eles empreendida, pois o princípio da conquista era o estabelecimento da ordem e da justiça. Esta ideologia servia para legitimar o imperialismo assírio ${ }^{19}$.

No período neoassírio, os reis assírios fizeram um esforço para conquistar os territórios da Síria-Palestina e os motivos econômicos foram uma das principais razóes para esta conquista. A região costeira do Mediterrâneo tinha um clima diferente da Assíria, assim como sua produção agrícola. Além disso, nesta regiáo encontravam-se as cidades fenícias que atuavam como importantes centros de negócios. O comércio era controlado pelo Estado e a cobrança de tributos trouxe benefícios econômicos para o centro do império, pois a Assíria obtinha bens e matérias-primas livremente. Mas, se a economia foi o principal motivo para a expansão territorial, é notável perceber que os textos assírios mencionam a ideologia real para a dominação política. Estes textos pregam a proeminência do deus Aššrur sobre todas as divindades e que todos os povos da Terra devem reconhecer o rei assírio como o representante de Aššur ${ }^{20}$.

\footnotetext{
${ }^{18}$ P.R., BEDFORD. "Neo-Assyrian Empire". In: I., MORRIS; W., SCHEIDEL. (eds.). The Dynamics of Ancient Empires. State Power from Assyria to Byzantium. Oxford; New York: Oxford University Press, 2009, p.44.

${ }^{19}$ M., LIVERANI. Para além da Bíblia. História Antiga de Israel. São Paulo: Paulus; Loyola, 2008,p.192.

${ }^{20}$ P.R., BEDFORD. "Neo-Assyrian Empire". In: I., MORRIS; W., SCHEIDEL. (eds.). The Dynamics of Ancient Empires. State Power from Assyria to Byzantium. Oxford; New York: Oxford University Press, 2009, p.48.
} 
Neste período, os estados da Síria-Palestina subjugados tornaram-se "clientes", isto é, reconheciam o deus Aššur como o maior dos deuses, pagavam tributos aos assírios e mantinham certa independência política com seus reis locais. A legitimidade do rei local dependia da sua lealdade ao rei assírio e da "obediência dos deuses locais ao deus Aššur", expressa nos rituais religiosos oficiais. O cliente tinha direito de manter sua identidade própria, mas estava submetido ao universo simbólico assírio ${ }^{21}$.

Mas, além dos clientes, os assírios criaram outra categoria de Estado subjugado: a "província" do império, na qual estavam englobadas as terras e as suas populaçôes. Esta concepção do espaço legitimava as deportaçôes, pois estes povos tornavam-se assírios e, assim, passavam a habitar o território assírio ${ }^{22} \mathrm{em}$ toda a sua extensão. As deportaçóes funcionavam como um mecanismo para "quebrar" antigas identidades e reconstruir novas e sua prática favoreceu a difusão da língua aramaica em todo o império ${ }^{23}$.

Todos os territórios e povos conquistados estavam incluídos no império assírio, na categoria de cliente ou de província, porém havia uma diferença entre a identidade nacional e étnica assíria e a identidade do império assírio. Um povo que mantivesse uma relação de clientela era visto, politica e ideologicamente, como inferior, já os povos conquistados e anexados como uma província, tornavam-se parte integrante do império assírio e eram assimilados à identidade étnica assíri ${ }^{24}$. E esta prática é referida por vários soberanos assírios, como testemunha este texto dos Anais de Sargão $\mathrm{II}^{25}$ :

Gente da quatro partes do mundo, de língua estrangeira e de idioma incompreensível, habitantes de montanhas e de planuras, todos os súditos da luz dos deuses e senhor de tudo, eu os transportei por ordem de Aššur

\footnotetext{
${ }^{21}$ Ibidem, p. 54 .

${ }^{22}$ Há indícios que a prática da "deportação cruzada" (pessoas de diversos lugares sendo deslocadas ao mesmo tempo) teria envolvido cerca de 4,5 milhóes de pessoas em um período de três séculos (Liverani, 2008, p. 193).

${ }^{23}$ M., LIVERANI. Para além da Bíblia. História Antiga de Israel. São Paulo: Paulus; Loyola, 2008, p.194.

${ }^{24}$ P.R., BEDFORD. "Neo-Assyrian Empire". In: I., MORRIS; W., SCHEIDEL. (eds.). The Dynamics of Ancient Empires. State Power from Assyria to Byzantium. Oxford; New York: Oxford University Press, 2009, p.61.

${ }^{25}$ M., LIVERANI. Para além da Bíblia. História Antiga de Israel. São Paulo: Paulus; Loyola, 2008, p. 192.
} 
meu senhor e pelo poder de meu cetro. Eu os fiz se tornarem de uma só língua e os insidiei ali. Designei-lhes assírios como escribas e vigilantes, capazes de lhes ensinar o temor de deus e do rei.

Segundo Liverani ${ }^{26}$ : "O objetivo final é uma assimilação linguistica, cultural, política o mais completa possivel, de modo a transformar os vencidos em assirios". Mas do ponto de vista local, das populaçôes conquistadas, isto representava um processo de perda de identidade cultural extremamente grave.

\section{A conquista Assíria de Lakiš: contribuiçóes da Arqueologia e da Iconologia}

No mundo mesopotâmico, o relevo sobre pedra foi uma das mais importantes manifestaçôes artísticas. Os mais usados foram os baixos-relevos sobre lajes de alabastro, repartidas em duas ou mais partes, recobrindo as paredes dos palácios, podendo ultrapassar $2 \mathrm{~m}$ de altura. Seis reis assírios deixaram este tipo de relevo: Assurnazirpal II (883-859 a. C.); Salmanassar III (853-824 a. C.); Teglatphalassar III (745-727 a. C.); Sargão II (722-705 a. C); Senaqueribe (705-681 a. C.) e Assurbanipal (669-627 a. C.).

A prática cultural da criação destes relevos monumentais está associada ao momento político da construção de grandes impérios. A maioria das cenas representadas evocam a guerra $\mathrm{e}$ as campanhas militares empreendidas pelos assírios contra seus inimigos.

Entendemos que o estudo de fontes imagéticas da representação da religiáo e da guerra na Assíria do I milênio a. C. amplia os conhecimentos deste período, já desenvolvidos a partir das fontes epigráficas publicadas. Dentre estas, destaca-se a monumental obra "Chroniques Mésopotamiennes", onde J.J. Glassner (1993) apresenta e traduz documentos da historiografia mesopotâmica. Estes textos compóem uma narrativa oficial sobre a história da Mesopotâmia e, por isso, tornam-se fontes históricas de primeira grandeza. Dentre estas, destacamos a série de crônicas assírias que narram a história política e militar do período neoassírio que, segundo Glassner ${ }^{27}$ :

\footnotetext{
${ }^{26}$ Idem.

${ }^{27}$ J.-J., GLASSNER. Chroniques Mésopotamiennes. Paris: Les Belles Lettres, 1993, p.111.
} 
A cette époque, l'imperialisme assyrien, fort de son idéologie universaliste, a assimilé la guerre à une lute contre les forces du mal. Conçue comme une épreuve ordalique, la guerre est devenue un élément constitutif de l'ordre cosmique. Elle sauve la civilisation, le roi étant l'instrument de la justice divine, et le dieu Assur se parant d'une figure guerrière. (...) Le statut d'inimitié et de négativité de l'ennemi fait que les destructions et les ravages prennent un caractère positif. Le roi assyrien est toujours bon et juste, l'ennemi menteur, mauvais et impur. Les historiens assyriens, serviteurs zélés du prince, répercutent cette idéologie officielle. ${ }^{28}$

Vemos que esta concepção de imperialismo é de grande atualidade no mundo contemporâneo, pois há valores e ideologias que, metamorfoseados, permaneceram ao longo do tempo. As ideologias podem fazer uso de símbolos culturais para encobrir as relaçôes de desigualdade e dominação, servindo para legitimar os interesses do grupo hegemônico no poder. Um importante mecanismo de hegemonia é o de transformar valores e interesses específicos de um determinado grupo, em valores e interesses universais e atemporais.

Mas Postgate ${ }^{29}$ alerta para a questão da crítica interna às fontes, quando diz que: "with war, perhaps more than any other subject, we are prisoners of what the Mesopotamian rulers wanted us to know: both their royal inscriptions and the public art are essentially propaganda, and we must be more cautions than ever about reading between the lines" ${ }^{30}$ Para tanto, utilizamos a metodologia de análise de imagens preconizada pela iconologia, cujo postulado divide o processo de análise visual em três momentos: realização da descrição préiconográfica, que é a enumeração dos motivos artísticos para cada temática; realização da análise iconográfica, com a identificação de imagens, estórias e

\footnotetext{
${ }^{28}$ Nesta época, o imperialismo assírio, convencido de sua ideologia universal, assimila a guerra a uma luta contra as forças do mal. Concebida como uma experiência ordálica, a guerra tornou-se um elemento constitutivo da ordem cósmica. Ela salva a população, sendo o rei o instrumento da justiça divina, e o deus Assur vestido como uma figura guerreira. (...) O estatuto de inimizade e de negatividade do inimigo faz com que as destruiçóes e as devastaçóes adquiram um caráter positivo. O rei assírio é sempre bom e justo, o inimigo mentiroso, mau e impuro. Os historiadores assírios, servidores zelosos do príncipe, repercutem esta ideologia oficial.

${ }^{29}$ J.N., POSTGATE. Early Mesopotamia. London and New York: Routledge, 1992, p.241.

${ }^{30} \mathrm{Com}$ a guerra, talvez mais do que qualquer outro tema, nós somos prisioneiros do que os reis mesopotâmicos queriam que soubéssemos: tanto suas inscrições reais como a arte pública são, essencialmente, propaganda, e nós devemos ter, mais que nunca, muito cuidado relativamente à leitura das entrelinhas.
} 
alegorias e a realização da interpretação iconológica, que é a descoberta e a interpretação dos valores simbólicos nas imagens ${ }^{31}$.

O sítio arqueológico de Nínive, atualmente território do Iraque, conheceu várias campanhas de escavaçóes entre os anos de 1852 e 1932. Estas escavaçôes identificaram dois palácios: um localizado a sudoeste, construído por Senaqueribe e conhecido com o "palácio sem rival" e outro, na parte norte do sítio, construído por Assurbanipal ${ }^{32}$. Na figura abaixo (Fig. 3), identifica-se o palácio norte à esquerda e o palácio sudoeste à direita.

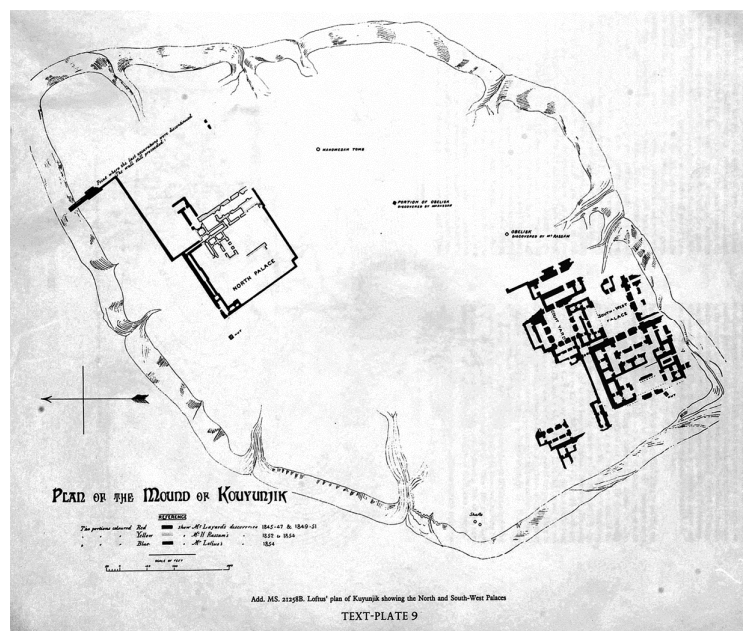

Fig. 3 - Plano de Nínive ${ }^{33}$.

Dentre as importantes produções artísticas assírias, algumas esculturas encontram-se no palácio sudoeste de Senaqueribe, em Nínive, um conjunto de relevos retratando as representaçốes da conquista da cidade de Lakiš (Figs. $4 \mathrm{e}$ 5). Localizada na área agrícola mais fértil de Judá, Lakiš era o centro regional mais influente do governo real judaico e a segunda cidade em importância

${ }^{31}$ E., PANOFSKY. Estudos de Iconologia. Lisboa: Editorial Estampa, 1995, passim.

${ }^{32}$ J.M., RUSSELL. "Sennacherib's Palace Without Rival Revisited: Excavations at Nineveh and the British Museum Archives". In: S., PARPOLA; R., WHITING. Assyria 1995. Helsinki: University of Helsinki, 1997, p.295.

${ }^{33}$ R.D., BARNETT. Sculptures from the north palace of Ashurbanipal at Nineveh (668-627 B. C.).

London: The British Museum Publications, 1976, p.24. 
depois de Jerusalém. Esse relevo, com cerca de $18 \mathrm{~m}$ de comprimento e $2,7 \mathrm{~m}$ de altura, foi descoberto por Henry Layard em 1853 e está, atualmente, no British Museum, em Londres.

Estes relevos se referem as batalhas realizadas com o objetivo de conter a revolta palestina contra os assírios de 705 a.C., quando os exércitos do Egito, da Fenícia, da Palestina, sob o comando de Judá, estiveram envolvidos na rebeliāo. Pesquisas arqueológicas identificaram a destruição de cidades como Lakiš, Arad e Beer Shaba ${ }^{34}$. O papel fundamental desempenhado por Lakiš nestes eventos é confirmado no texto bíblico em 2 Reis 18,14,17;19,8.

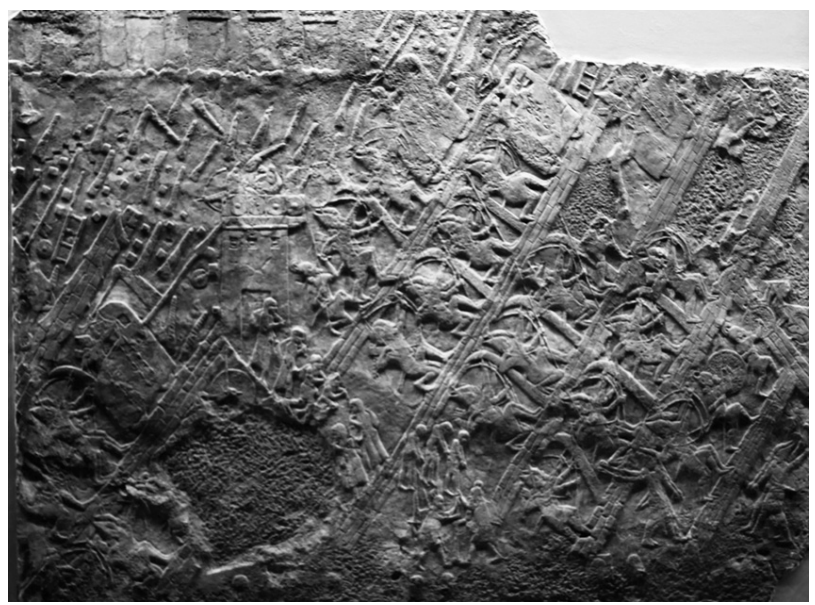

Fig. 4 - Sala de Lakišs, British Museum. Foto da Autora, 2011.

\footnotetext{
${ }^{34}$ B., OTZEN. "Israel under the Assyrians". In: M.T., LARSEN. (ed.). Power and Propaganda. A symposium on ancient empires. Copenhagen: Akademisk Forlag, 1979, p.258. 


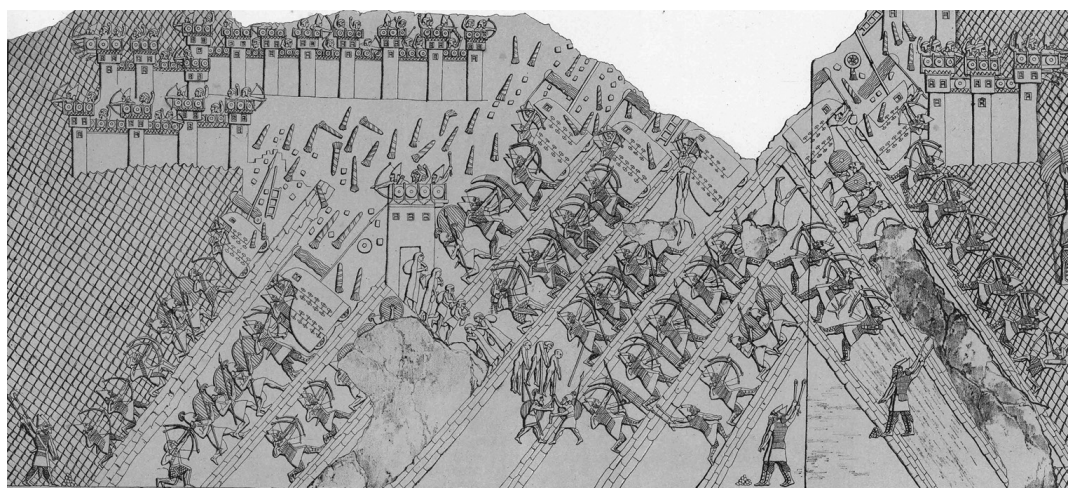

Fig. 5 - LAYARD, 1853: 36, prancha 21.

Neste relevo parietal vemos a cidade de Lakiš sendo atacada pelo exército assírio. $\mathrm{Na}$ descrição iconográfica destacam-se trinta e dois arqueiros, três em cada torre da fortaleza, abaixo se veem soldados em fila derrubando as muralhas da cidade, sendo que alguns estão arremessando pedras, outros possuem lanças e escudo e há ainda soldados dirigindo um carro de guerra que está destruindo as muralhas da cidade. Na parte central esquerda do painel há pessoas deportadas saindo da muralha, em meio aos soldados em luta subindo a rampa. Estas rampas, aqui representadas por linhas diagonais, foram construídas pelo exército assírio como tática de acesso à cidade fortificada. Vemos soldados arremessando tochas sobre o exército assírio e estes revidam com pedras.

A descrição assíria da guerra em Judá é apresentada nos textos conhecidos como Anais de Senaqueribe ${ }^{35}$ :

Quanto a Ezequias, o judeu, ele não se submeteu ao meu jugo. Eu sitiei 46 de suas fortes cidades, fortes murados, e inúmeras aldeias, na sua vizinhança, e (as) conquistei mediante rampas bem construídas e aríetes que cercavam (os muros), (combinado com) o ataque de soldados a pé, e (usando) minas, brechas nas paredes. Eu expulsei 200.150 pessoas, jovens e velhos, homens e mulheres, cavalos, mulas, asnos, camelos, gado maior e menor sem conta, e (os) considerei butim. Ele mesmo, eu o fiz prisioneiro em Jerusalém, em sua

${ }^{35}$ J.B., PRITCHARD. Ancient Near Eastern Texts, Relating to the Old Testament, $3^{\text {a }}$ edição com suplementos, Princeton, 1969, p.288. 
residência real, como um pássaro em uma gaiola. Eu cerquei com rampas a fim de alcançar os que abandonavam a porta da cidade. Suas cidades que eu saqueei, eu as tomei de seu país e as entreguei todas a Motinti, rei de Ašdod, a Padi, rei de Eqrón, e a Sillibel, rei de Gaza. Assim reduzi o seu país, mas aumentei o seu tributo e os presentes katrū (devidos) a mim (como seu) superior, que lhe impus.

$\mathrm{Na}$ sequência dos relevos temos outras lajes que mostram a peregrinação dos deportados (Fig. 6 - foto de detalhe).

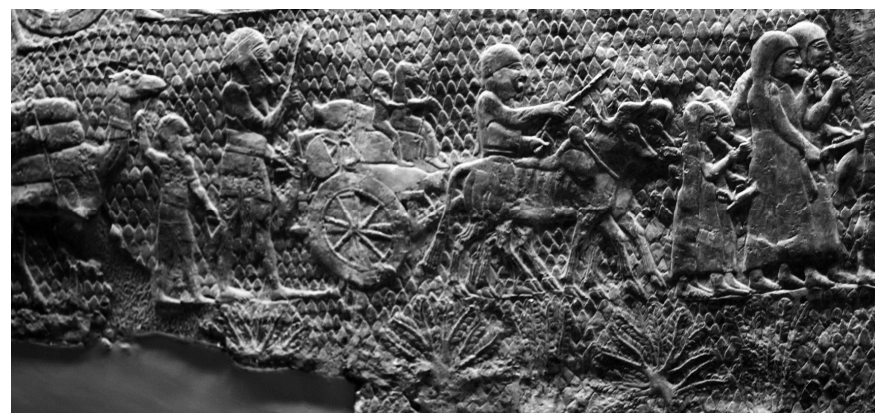

Fig. 6 - Sala de Lakišs, British Museum. Foto da Autora, 2011.

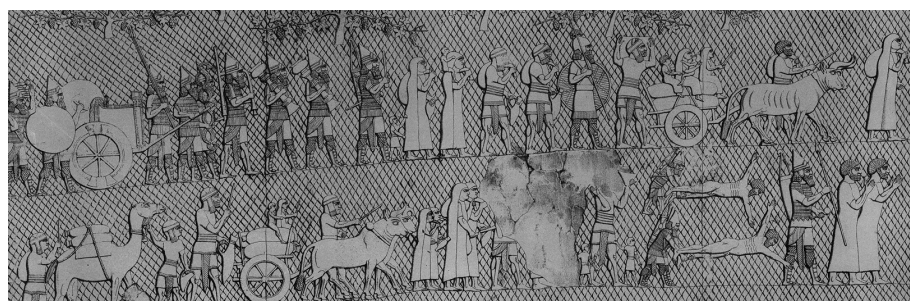

Fig. 7 - LAYARD, 1853: 37, prancha 22.

Os cativos estão sendo conduzidos pelo exército do rei assírio, veem-se soldados assírios portando objetos oriundos do saque, enquanto outros conduzem os deportados, dentre eles vê-se um homem carregando uma criança nos ombros, os outros levam seus pertences. Esta é uma das raras cenas do mundo mesopotâmico onde as mulheres estão representadas! Aqui elas são prisioneiras de guerra deportadas, algumas estão a pé, outras, acompanhadas de crianças, estão conduzindo uma carroça com butim de guerra. Na linha inferior vemos homens deportados conduzindo um camelo com pertences, carroças 
levadas por bois, seguidas de crianças e mulheres. Observa-se, ainda, uma cena de terrível castigo - o esfolamento, infligido a soldados inimigos que teriam se rebelado.

E, na Fig. 8, abaixo, como última etapa do processo de conquista, o conjunto de lajes mostra o rei Senaqueribe, ainda no campo de batalha, recebendo oficiais capturados do exército do reino de Judá e os bens confiscados pelos soldados assírios.

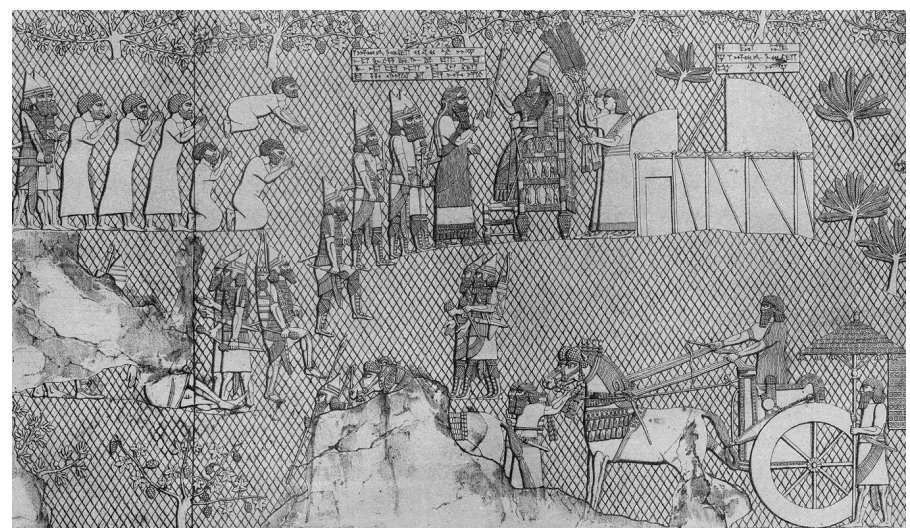

Fig. 8 - LAYARD, 1853: 38, prancha 23.

Notam-se prisioneiros judeus, usando vestes longas, com as mãos prostradas, seguindo o cortejo de soldados assírios, estão em posição de adoração ao rei Senaqueribe. Acima da representaçáo do rei, temos uma inscrição cuneiforme que $\mathrm{diz}^{36}$ :

\author{
${ }^{I d} 30-P A P . M E S ̌-S U$ šárru ŠÚ šárru KUR aš-šur \\ ina GIŠ.GU.ZA né-me-di ú-šib-ma \\ šal-la-at URU la-ki-su \\ ma-ha-ar-šu e-ti-iq ${ }^{37}$
}

\footnotetext{
${ }^{36}$ J.M., RUSSELL. "Sennacherib's Palace Without Rival Revisited: Excavations at Nineveh and the British Museum Archives". In: S., PARPOLA; R., WHITING. Assyria 1995. Helsinki: University of Helsinki, 1997, p.287.

${ }^{37}$ Senaqueribe, rei do mundo, rei da Assíria, sentado em um trono-nêmedu, enquanto o espólio de Lakiš passou diante dele.
} 
Diante do rei vemos a figura de um homem, com manto bordado, que provavelmente é um general de seu exército. $\mathrm{O}$ soberano, que aparece empunhando seu cetro, está sentado no trono, cercado por dois eunucos com abanadores. Eles encontram-se na frente da tenda real, em pleno acampamento militar. No relevo identificamos, acima da tenda, uma inscrição cuneiforme, que $\operatorname{diz}^{38}$ :

\author{
za-ra-tum \\ šá Id 30-PAP.MEŠ-SU \\ LUGAL KUR aš-šur ${ }^{39}$
}

Os estudos arqueológicos empreendidos pela equipe de David Ussishkin $^{40}$ (1996, p. 5), no sítio de Lakiš, confirmam as informaçôes dos textos e dos relevos assírios:

\begin{abstract}
A conquista de Laquish por Senaqueribe, rei da Assíria, durante a sua campanha contra Judá, em 701 a. C., é único na história e arqueologia do período bíblico. Este evento dramático é iluminado pelo Antigo Testamento, os registros assírios, as escavaçōes arqueológicas e os relevos assírios. Em 705 a. C. Senaqueribe subiu ao trono da Assíria e logo foi confrontado com uma revolta organizada por Ezequias, rei de Judá. Em 701

a. C. Senaqueribe marchou para a regiāo e, finalmente, invadiu Judá, onde a sua atenção estava focada principalmente na cidade de Laquish. Laquish foi a cidadela mais formidável em Judá, e sua conquista e destruiçâo foram a tarefa primordial da frente de batalha para Senaqueribe, quando ele veio para esmagar o poder militar de Ezequias. Na verdade, como indicado pelos relevos, a conquista de Laquish foi de singular importância e uma grande conquista militar, uma vez que nenhuma outra vitória havia sido registrada por Senaqueribe em uma exposição tão pródiga.
\end{abstract}

Como afirmam Finkelstein e Silberman ${ }^{41}$, as evidências materiais

\footnotetext{
${ }^{38}$ J.M., RUSSELL. "Sennacherib’s Palace Without Rival Revisited: Excavations at Nineveh and the British Museum Archives". In: S., PARPOLA; R., WHITING. Assyria 1995. Helsinki: University of Helsinki, 1997, p.288.

${ }^{39}$ Tenda de Senaqueribe, rei da Assíria.

${ }^{40}$ D., USSISHKIN. http://www.tau.ac.il/humanities/archaeology/projects/proj_past_lachish.html. p. 05

${ }^{41}$ I., FINKELSTEIN; N.A., SILBERMAN. A Bíblia não tinha razão. São Paulo, Girafa, 2003, p. 254 .
} 
encontradas nas pesquisas arqueológicas no sítio de Lakišs, revelam a luta brutal para defendê-la do cerco assírio:

A cidade foi toda queimada (...). Centenas de pontas de flechas foram encontradas no pé da muralha; enormes pedras arredondadas pela erosão, perfuradas durante o ataque, (...) arremessadas das rampas pelos defensores, para destruir as máquinas assírias de guerra - , foram recuperadas perto do ponto de assalto à muralha. Uma sepultura coletiva, com cerca de 1.500 pessoas - homens, mulheres e crianças -, foi achada nas cavernas perto dos declives no lado oeste do cômoro, misturada com restos de cerâmica do final do século VIII a.C.

Lakiš se configura em um raro exemplo, onde os dados arqueológicos e as fontes documentais contemporâneas ao evento complementam e asseveram uma narrativa visual. A representação plástica da batalha de Lakiš, feita pelos artistas assírios, retrata com grande fidedignidade os eventos ocorridos. Assim, os relevos assírios evidenciam certa verdade histórica, ainda que sejam banhados em um discurso ideológico e propagandístico.

\section{Conclusáo}

Para os mesopotâmicos, a habilidade da guerra, da pilhagem e do saque estavam entre os aspectos de um comportamento civilizado, assim como hábitos culturais e alimentares de comer pão, beber cerveja, banhar-se e vestir roupas limpas, como nos ensina a Epopeia de Gilgameš ${ }^{42}$.

A utilização de conceitos religiosos para legitimar invasôes territoriais e o extermínio de populaçôes subjugadas foi e continua sendo, uma prática humana, da Antiguidade ao mundo contemporâneo. Na Assíria, justificativas éticas e morais eram construídas para cada guerra decretada. Os deuses deveriam ser consultados, através da leitura das entranhas de animais sacrificados, preces e rituais religiosos que eram efetuados em pleno campo de

${ }^{42}$ F., MALBRAN-LABAT. Gilgamesh. Paris: Éditions du Cerf, 1988, passim. 
batalha, pois era preciso obter a aprovaçáo divina para cometer atos de barbárie. Era imperioso realizar uma guerra justa e santa! ${ }^{43}$.

As representaçóes iconográficas e os textos serviram como propaganda política e religiosa, com o objetivo de legitimar o poder dos governantes perante seus súditos. Mas também foram objeto de admiração da própria realeza, em uma tentativa de perpetuação de sua imagem e, assim, de seu poder ${ }^{44}$. Esses relevos monumentais foram expostos nas paredes internas dos palácios e, portanto, sua circulaçấo era restrita aos convidados do rei, às delegaçóes diplomáticas estrangeiras e à própria corte assíria. Os reis assírios construíram palácios para servir de núcleo administrativo, mas também como instrumento de propaganda, decorado de modo a impor ao visitante a impressão da esmagadora potência assíria. Essa decoração fazia, essencialmente, a exaltação da pessoa do rei e da evocação de seus altos feitos para seus contemporâneos e para "os que viessem depois". Entendemos que essas imagens não são uma cópia do real, mas narrativas construídas, a partir da perspectiva assíria sobre o acontecido.

Podemos afirmar ainda que ideologias políticas e sistemas de crenças são capazes de se adaptar e sobreviver em condiçôes significativamente diferentes das que tenham sido engendradas. Assim, o império assírio, na segunda metade do século IX e primeira metade do século VIII a. C., sobreviveu parcialmente pela força de suas relaçôes simbólicas e ideológicas.

${ }^{43}$ Z., BAHRANI. Rituals of War - The body and violence in Mesopotamia. New York: Zone Books, 2008, p.215.

${ }^{44}$ K.M.P., POZZER. "Uma História Assíria: o espetáculo do terror em uma composição artística". In: C.B., ROSA; J.B., MARQUES; A.B., TACLA; N.M., MENDES (Orgs.). A Busca do Antigo. Rio de Janeiro: Nau Editora, 2011, passim. 